\title{
Hacerse de una vida en tiempos del multiculturalismo neoliberal
}

\section{Q Luis Acatzin Arenas Fernández ${ }^{1}$}

1 Seminario de Investigación Permanente "Poder, Clase y Cultura", Instituto de Ciencias Sociales y Humanidades “Alfonso Vélez Pliego", Benemérita Universidad Autónoma de Puebla (ICSyH-Buap), Puebla, México.

Programa de Doctorado en Antropología Social, Centro de Investigaciones y Estudios Superiores en Antropología Social sede Sureste (Ciesas), San Cristóbal de las Casas, México.

ORCiD: 0000-0001-5975-1499

Correo electrónico: acatzin.arenas.fdez@gmail.com
Recibido

septiembre de 2019

Aceptado

abril de 2020

doi: $10.34096 /$ cas.i51.8271

\section{Resumen}

Alrededor de la pirámide de Cholula, México, es común encontrarse con los "guardianes de la tradición" realizando rituales dancísticos de inspiración prehispánica. Con la intención de contribuir a preservar dichas tradiciones, el turismo suele brindarles "cooperaciones" económicas. Si bien esta relación entre danzantes y turistas permite la circulación de efectivo y es en sí misma una forma de "ganarse la vida", suele ser descrita tan solo como una actividad cultural. El objetivo del presente documento es mostrar cómo el trabajo conjunto de la lógica neoliberal y multicultural, aprovechando y reproduciendo las diferencias y la desigualdad, ha abierto espacios en el mercado que permiten, de manera simultánea, una forma de ganarse la vida que no es reconocida como actividad económica, formas ambiguas de dar valor a la vida y la construcción de expectativas optimistas a pesar de la incertidumbre en que se vive.

\section{Making a living in times of neoliberal multiculturalism}

\author{
Abstract \\ Around the pyramid of Cholula, Mexico is common to meet the "guardians of tradition" \\ performing dance rituals of pre-Hispanic inspiration. With the intention of contributing \\ to preserve these traditions, tourism usually provides economic "cooperations." Despite \\ this relationship between dancers and tourists allows the circulation of cash and is in \\ itself a way of "earning a living", it is usually described only as a cultural activity. This \\ paper argues that neoliberal and multicultural logics operate jointly, taking advantage \\ of and reproducing differences and inequality. This paper aims to show how these
}

\section{Palabras clave}

Ganarse la vida; Darle valor a la vida; Proletariado multicultural; Ideología; Multiculturalismo

\section{Key words}

Earning a living; Giving value to life; Multicultural proletariat; Ideology; Multiculturalism 
logics have opened spaces in the market that allow simultaneously: - a form of earning a living that is not recognized as an economic activity, - ambiguous ways of giving value to life, - and the construction of optimistic expectations despite the uncertainty in which people live.

\section{Fazerse de uma vida em tempos do multiculturalismo neoliberal}

\section{Resumo}

Palavras-chave

Ganhar-se a vida; Dar-lhe valor à vida; Proletariado multicultural; Ideologia; Multiculturalismo
1. Los nombres de los informantes citados fueron modificados.

2.

El programa de Pueblos Mágicos (actualmente Programa de Desarrollo Regional Turístico Sustentable y Pueblos Mágicos PRODERMAGICO), en México, fue creado en 2001 por el gobierno federal desde la Secretaría de Turismo. Se trata de una estrategia de captación de turismo nacional y extranjero que, si bien propone aprovechar y reconocer la diversidad del país, suele ser motor de la invención de tradiciones y la reproducción de imágenes e identidades estereotipadas. Los municipios poblanos de San Andrés Cholula y San Pedro Cholula fueron reconocidos en 2012, de manera conjunta, como "Cholula Pueblo Mágico".
No México, ao redor da pirâmide de Cholula, é comum encontrar os "guardiães da traição" realizando rituais de dança de inspiração pré-hispánica. Com a intenção de contribuir à preservação das tradições, o turismo costuma brindar-lhes "cooperações" econômicas. Ainda que esta relação entre dançarinos e turistas permita a circulação de dinheiro vivo, e seja em si mesma uma forma de "ganhar a vida", costuma ser descrita tão só como uma atividade cultural. O objetivo do presente documento é mostrar como o trabalho conjunto da lógica neoliberal e multicultural, se aproveitando e reproduzindo as diferenças e as desigualdades, têm aberto espaços no mercado, os quais permitem de maneira simultânea uma forma de se ganhar a vida que não é reconhecida como atividade econômica, formas ambíguas de dar valor à vida, assim como a construção de expectativas otimistas apesar da incerteza em que se vive.

\section{Introducción}

Durante buena parte del día, Xiuhtecuhtli, Coyoltzin y Ameyal ${ }^{1}$ visten trajes hechos con pieles de diferentes animales y portan penachos con plumas de distintos tamaños y colores. Cada uno por su cuenta, con diferentes grados de éxito, busca espacios en el borde que rodea la zona arqueológica de Cholula, lugar en el que se encuentra la base piramidal más grande del mundo, con la intención de establecer contacto con el turismo que visita este Pueblo Mágico. ${ }^{2}$ Los danzantes del llamado movimiento de la mexicanidad, organización de tipo político-cultural que cuenta con una larga historia (De la Peña, 2002; De la Torre, 2007; Galinier y Molinié, 2013), realizan danzas de inspiración prehispánica, rituales de purificación con humo de copal y hablan frente a la gente que se detiene a verlos sobre la importancia del rescate y defensa de las "verdaderas" tradiciones de los mexicanos, que son las que, de acuerdo con ellos, tienen su origen en la cultura previa a la llegada de la población europea a América. Al interactuar con el turismo, los danzantes hacen un llamado a respetar la cultura original de Cholula, a admirar su belleza y a establecer lazos de solidaridad que permitan que dicha cultura y sus tradiciones sean preservadas. Los turistas suelen responder con aplausos, felicitaciones, agradecimientos, se toman fotos con ellos y usualmente les brindan una "cooperación", la cual se deposita de manera voluntaria en un canasto que se encuentra frente al pequeño altar improvisado en el lugar donde se lleva a cabo el ritual.

Esta relación entre danzantes y turismo es alentada por las administraciones municipales de San Andrés y San Pedro Cholula, pues se considera que mediante su labor se contribuye a la difusión cultural, para que tanto visitantes como población local puedan conocer y experimentar ciertas tradiciones lugareñas. Dicha labor les ha abierto las puertas en diferentes espacios a los que son invitados a participar: eventos públicos 
promovidos por el Gobierno municipal y estatal, rituales en las fiestas patronales promovidas por organizaciones barriales, por ejemplo; además, es común que empresarios y comerciantes que tienen negocios en la zona los convoquen para hacer muestras culturales. Por estos motivos, han sido llamados los "guardianes de la tradición".

Estos son presentados, y se presentan a sí mismos, como encarnación de la cultura, al menos de aquella que se promueve desde el sentido común y que es catalogada como un bien inmaterial que debe ser rescatado, conservado y compartido/difundido (Organización Mundial del Turismo, 2001). Quienes interactúan y convocan a los danzantes nunca hablan acerca de sueldos ni pagos por la presentación de sus rituales. En su lugar, se utiliza la palabra "cooperación", esto es, ni los representantes de gobierno, empresarios, comerciantes y turistas se piensan a sí mismos como meros consumidores de cultura ni como empleadores de aquellos, más bien, se presentan como promotores culturales que establecen relaciones de solidaridad y mecenazgo. De la misma forma, cuando los danzantes reparten los recursos obtenidos después de hacer ceremonias, llaman "cooperación" al dinero que obtienen; de tal forma que el estatus bajo el cual se conciben no es como trabajadores ni prestadores de servicios, sino, precisamente, como guardianes de la tradición. De acuerdo a mis informantes, aquellos que realizan danzas en espacios públicos tienen prohíbido por las administraciones municipales cobrar o pedir cuotas establecidas al turismo. Al mismo tiempo, ellos evitan hablar en terminos de relaciones mercantiles pues, a fin de cuentas, "la cultura no es mercancía".

La "cooperación" que reciben puede ser en dinero, en especies (alimentos, materias primas, instrumentos y plumas de aves para sus trajes), o en la forma de permisos oficiales para hacer uso de plazas públicas. En ocasiones, cuando participan en eventos organizados por el Gobierno pueden no recibir nada a cambio. De este modo, bajo la noción de "cooperación", la "esfera" de lo cultural toma tal relevancia que disimula las relaciones políticas y económicas presentes en la demostración de rituales. Como se verá más adelante, los danzantes pueden ser conscientes de la labor económica que realizan; no obstante, el argumento cultural que recubre sus actividades es tanto parte de sus estrategias para lograr la reproducción de la vida como una forma de darles mayor valor a sus vidas.

Puesto que para lograr la reproducción de la vida el capitalismo empuja al grueso de la población a entrar en relaciones sociales en las que esta solo cuenta con su fuerza de trabajo -manual e intelectual-, en el presente artículo se parte en primera instancia de la noción de "ganarse la vida" (Denning, 2010) para entender la manera en que el capitalismo ejerce una fuerza estructurante en la vida de la gente. El caso que nos ocupa es una buena oportunidad para describir y analizar cómo el modo de producción vigente ha abierto, de manera indirecta y mediante una idea general sobre la cultura, espacios en el mercado que permiten ganarse la vida y, al mismo tiempo, intentar dotarla de valor y sentido. Sin embargo, esta lucha diaria por "hacerse de una vida" (Narotzky y Besnier, 2014) se encuentra limitada por las condiciones en que se realiza. Por ello, tomando como referencia las reflexiones de Susana Narotzky y Niko Besnier en torno a los conceptos de crisis, valor y esperanza, se presentarán de manera paralela las nociones de incertidumbre, optimismo y valor (económico y moral), con la intención de evidenciar cómo el trabajo de las ideologías dominantes en el neoliberalismo, el multiculturalismo y el emprendedurismo generan formas específicas de enfrentar y evadir la incertidumbre (crisis), de pensar la cultura como fuente de dignidad y recursos (valor), y de construir expectativas optimistas hacia el futuro (esperanza).

Para poder realizar el presente análisis, se utilizaron datos obtenidos a partir del trabajo de campo realizado con diferentes grupos de danzantes en los municipios de San Andrés Cholula y San Pedro Cholula. El trabajo etnográfico se llevó a cabo en el año 2016, en un primer periodo de casi cuatro meses, de junio a mediados de septiembre. 
Posteriormente, se realizaron temporadas de campo cortas durante 2016 y 2017. El resultado final fue la presentación de la tesis de maestría "La cultura no es mercancía": etnicidad, proletariado y subjetividad entre los danzantes de la mexicanidad en Cholula, Puebla (Arenas, 2018a), misma que fue aprobada por un comité en enero de 2018. La perspectiva teórica desde la que se desarrollan tanto el trabajo de tesis como el presente documento es la de una antropología con enfoque de economía política.

\section{La economía de la diferencia}

David Harvey ha señalado que el capitalismo no inventó las diferencias entre personas, no inventó la otredad, sin embargo, ha sabido administrarla, promoverla y explotarla (Harvey, 2012). Las diferencias raciales, étnicas, generacionales, de género, entre otras, ya existían antes de que el capitalismo se afianzara como modo de producción dominante. Lo propio del capitalismo es, por un lado, instrumentalizar estas diferencias para facilitar la acumulación de capital: ofrecer salarios más reducidos a los grupos más vulnerables -mujeres, niños, grupos étnicos no dominantes-; desviar el antagonismo entre capital/trabajo hacia el enfrentamiento entre grupos de trabajadores; y producir "vulnerabilidades utilizables", por ejemplo, la diferencia entre fuerza de trabajo legal e ilegal -migrantes sin ciudadanía- como una forma de "subsidio al capital" (Sider, 2003, p. 318). Por otro lado, el capitalismo requiere de otro tipo de diferencia, que es, a un mismo tiempo, condición de posibilidad y eje para su reproducción: aquella que se da entre quienes solo cuentan con su fuerza de trabajo como única opción para lograr la reproducción de la vida y quienes compran como mercancía o se benefician de manera indirecta de esa fuerza de trabajo para acumular capital.

No obstante, previo al surgimiento de la diferencia que emana de la oposición entre poseer capital y contar con capacidad de trabajo, fue necesaria la imposición de una forma específica de lograr la reproducción de la vida, una basada en lo que se ha llamado la liberación de fuerza de trabajo. Como ya lo ha dicho Michael Denning, "el capitalismo comienza no con la oferta de trabajo, sino con el imperativo de ganarse la vida" (Denning, 2010, p. 78). Estar libre de la posesión de los medios de producción implica tener que salir a ganarse la vida, valerse tan solo de la fuerza de trabajo con la que se cuenta; con ello se establece una relación de dependencia radical hacia el mercado (Denning, 2010) y, por lo tanto, se vive en una condición permanente de incertidumbre, de contingencia, debido al constante riesgo de que la fuerza de trabajo no se realice (Kawashima, 2009).

El proletariado, aquella población cuya vida está ligada a la incertidumbre del mercado, puede estar directamente ocupado por el capital -y pertenecer a alguna de las siguientes categorías: clase trabajadora tradicional, asalariados, ocupados, población activa- o puede tener una "relación de separación y distancia medida", característica principal de lo que Marx denominó superpoblación relativa o excedente relativo de población (Kawashima, 2009, p. 12) -los sin salario, desocupados o con trabajo intermitente, ejército industrial de reserva-. De este modo, "no se necesita un trabajo para ser proletario: la vida sin salario, no el trabajo asalariado, es el punto de partida para entender el libre mercado" (Denning, 2010, p. 79).

En la etapa actual del capitalismo, llamada por Ernest Mandel "capitalismo tardío" (Mandel, 1979), la propuesta posmoderna, denominada por Frederic Jameson como la lógica cultural de esta etapa (Jameson, 2012), y el discurso multicultural, el cual puede ser pensado como la ideología propia del posmodernismo (Žižek, 1998), se han generado nuevas formas de construir diferencias -las cuales han sido incorporadas al mercado- y de reivindicarlas. El posmodernismo, con su rechazo de las metanarrativas y su preferencia por la diversidad de voces, puso en el centro de atención a distintos 
grupos marginados. En la medida en que el multiculturalismo ha dividido el mundo en una multiplicidad de pequeñas culturas, cada grupo marginado es pensado bajo esos términos.

Por su parte, el neoliberalismo, con su tendencia a la austeridad -privatización de servicios públicos-, la flexibilización laboral y la construcción de nuevos nichos de mercado para dar cauce a mercancías y capital acumulado (Harvey, 2012, 2015), ha construido un escenario en el que la población desposeída es orillada a buscar nuevos espacios para lograr la reproducción de la vida. El trabajo conjunto de la propuesta posmoderna y multicultural con la lógica neoliberal tiene, para el caso que aquí nos ocupa, dos implicaciones: por un lado, las diferencias -en particular, aquellas denominadas culturales- se han transformado en algo más que un instrumento para la acumulación de capital. Hoy en día también conforman nuevos nichos de mercado o se convierten en sustento del movimiento de capital. Las etnomercancías (Escalona, 2016) y la venta de la etnicidad (Comaroff y Comaroff, 2011) son buen ejemplo de ello. Por otro, se han multiplicado las formas de mantener una relación indirecta con el capital, entre las cuales se hallan aquellas actividades que permiten la reproducción de la vida pero que no son reconocidas como económicas, sino como meramente culturales. Ambas implicaciones pueden ser abordadas y sintetizadas desde lo que Harvey ha denominado "renta por monopolio" (Harvey, 2005).

Un elemento que colabora en el hecho de que ciertas actividades sean pensadas como culturales y que no se reconozca su vinculación con las actividades económicas puede ser hallado en la vigencia de un mapa cognitivo desfasado sobre cómo se concibe el trabajo y a los trabajadores (Arenas, 2019). Denning (2004) ha mostrado que, cuando pensamos en trabajadores -y por lo tanto, en proletariado-, la imagen con la que contamos es la del trabajador industrial, que tiene horarios establecidos, usa uniforme y participa directamente en la producción de plusvalor. Sin embargo, en estos tiempos de acumulación flexible, el capital ha desarrollado nuevas estrategias para convocar fuerza de trabajo de manera indirecta; esto a partir de mercados laborales en los que el salario y la relación patrón/empleado han desaparecido, pues la forma de beneficiarse del trabajo de otros no requiere de la explotación directa.

Los guardianes de la tradición podrán no participar en la producción de plusvalor como lo hacen los obreros industriales o los trabajadores en las grandes maquilas, no obstante, su presencia permite materializar aquellas características que hacen de "Cholula Pueblo Mágico" un lugar especial. Esto contribuye a la atracción de visitantes y, por lo tanto, se traduce en ganancias para quienes ofrecen servicios y mercancías al turismo. Es aquí donde la noción de renta por monopolio resulta útil para analizar esta dinámica.

La lógica del capitalismo implica que la posesión de propiedad privada de ciertas personas sobre ciertas partes del planeta se traduce en la producción de renta, de modo que monopolizar una mercancía, un espacio o un proceso genera ganancias (Harvey, 2005). De esta lógica se desprende la posibilidad de comercializar de manera indirecta elementos simbólicos, culturales, cuyo estatus no cambia a aquel de la propiedad privada. Me explico. Parafraseando a Harvey (2005), la abadía de Westminister y el palacio de Buckingham -propiedad de una nación- podrán no ser vendidas y con ello nunca pasarán a manos de propietarios privados. No obstante, su presencia es comercializable en la medida en que estos lugares y su poder simbólico logran atraer turismo, de modo que comercios, hoteles y quienes se dedican a la venta de ciertas mercancías y servicios dependen de ellos para aumentar sus ganancias. La renta de estos negocios -o al menos su aumento- surge de la posibilidad de monopolizar el valor simbólico de una arquitectura que es irrepetible, pues en ninguna otra parte del mundo será posible encontrar otra abadía de Westminister ni otro palacio de Buckingham. 
El argumento de Harvey puede ser complementado con algunas reflexiones desde el campo del turismo. MacCanell ha propuesto pensar el turismo como una "clase ociosa" que, impulsada por la ansiedad producto de un sentimiento generalizado de inestabilidad y falta de autenticidad en la vida diaria, busca experiencias y culturas auténticas y originales (MacCanell, 2013). Un elemento interesante sobre esta clase ociosa es que puede estar consciente de que la industria turística ofrece una autenticidad de escenario; no obstante, no duda de que lo original se encuentra "allá afuera". De acuerdo con Harvey, se trata de una contradicción propia de la mercantilización de la diferencia (Harvey, 2005). Sobre este mismo tema, Erik Cohen agrega que el turista tan solo necesita identificar algún rastro que parezca auténtico para entrar en el juego del "como si", esto es, "pretender que un producto artificial es auténtico, incluso si en el fondo no está convencido de su autenticidad" (Cohen, 1988, p. 383). Urry aborda el tema de la mirada del turista como producto de imágenes prefabricadas (por el cine, la televisión o la literatura), de modo tal que, "cuando el turista ve dos personas besándose en París lo que captura en la contemplación es el 'París romántico atemporal”' (Urry, 2018, p. 53), por lo tanto, el turista visitará París con estas imágenes de por medio.

Es común que aquello que se construye para el turismo sea recuperado como parte de la vida cotidiana y la "cultura" de las poblaciones locales. Jean y John Comaroff han señalado la existencia de estos procesos (Comaroff y Comaroff, 2011); no obstante, es Michael Picard quien ha profundizado en el tema. Para ello, propone el concepto de turistificación en pos de pensar cómo, lejos de suponer que la modernidad impacta "desde afuera" a las pequeñas culturas (perspectiva básica de la antropología), el constante contacto entre poblaciones construye eso que llamamos cultura. El caso balinés analizado por Picard es particularmente ilustrativo, pues tanto la noción misma del nacionalismo balinés, así como las danzas y los rituales sagrados y "auténticos" que la población practica han sido moldeados por diferentes etapas de interacción con Occidente; y el turismo es la última de las fuerzas que han influido en ello (Picard, 1997).

Este último punto expuesto por Picard es relevante al menos en dos sentidos. Por un lado, como ya se ha expuesto, la cultura no es la suma de persistencias que han logrado trascender la historia, y tampoco es el simple resultado de la imposición de una cultura externa. Mas bien, la cultura se construye de manera relacional. Por otro lado, si bien es cierto que en el capitalismo avanzado opera una retórica o ideología de la autenticidad (Frigolé, 2014), resulta importante resaltar que ese proceso de construcción de la cultura y de la autenticidad siempre implica negociación, tal como lo han mostrado Philip Feifan Xie (2011) y Beatriz Pérez (2006). Las poblaciones que reivindican identidades étnicas en el marco de la industria turística no son sujetos pasivos que reproducen ideas de manera mecánica. Estos sujetos echan mano de su creatividad y, mediante una constante negociación con turistas, gobierno y la población local, construyen, refinan y dinamizan aquellas representaciones identitarias que interesan al público que los observa, mismas que, en ciertos momentos, pueden ser movilizadas en la lucha política (Arenas, 2018c; Pérez, 2006).

La autenticidad, la invención de la tradición y la cultura parecen ser elementos de un mismo proceso que constantemente se pone en marcha. Este proceso, que vincula aquellos tres elementos, puede ser movilizado para generar rentas por monopolio. Los danzantes en Cholula encarnan los discursos sobre la posibilidad de experimentar la cultura de una de las ciudades prehispánicas más antiguas del continente americano; discursos que, a partir de un proceso hegemónico, gobierno y empresarios han elaborado para atraer turismo. Su presencia y las actividades culturales que realizan son una forma de generar renta por monopolio, no tanto para ellos mismos, sino para quienes se benefician de manera indirecta de su labor. Hasta aquí, es evidente que los danzantes entran en relaciones económicas, a pesar de que el argumento que justifica sus actividades se construya en términos meramente culturales. Sin embargo, esta 
explicación que vincula ambos elementos -economía y cultura- puede ser un tanto rígida y mecánica.

Para poder seguir desarrollando estas ideas hace falta partir de una definición de economía que no privilegie las nociones básicas de la economía clásica: intercambio, ganancia y cálculo. Pues, como lo han señalado Boltanski y Chiapello (2002), la simple búsqueda de beneficios nunca es motivación suficiente para que los sujetos realicen sus actividades en el capitalismo. Siguiendo a Narotzky y a Besnier, por economía deben entenderse "los procesos involucrados, de un modo u otro, en 'hacer una vida' tomado en un sentido amplio y remarcando el esfuerzo involucrado y el objetivo de sostener la vida" (Narotzky y Besnier, 2014, p. 5). Es importante resaltar que "hacerse de una vida" va más allá de solo mantenerse con vida, se trata de "hacer personas en su dimensión física, social, espiritual, afectiva e intelectual" (Narotzky y Besnier, 2014, p. 4). La perspectiva propuesta por estos autores, permite tomar en cuenta los intentos que la gente hace para ganarse la vida y, al mismo tiempo, construir una vida que valga la penar ser vivida; es decir, las luchas cotidianas por hacerse de una vida en sentido amplio.

Pero también, y este es uno de los objetivos principales en el presente documento, abre la puerta para pensar cómo estos intentos por hacerse de una vida pueden encontrarse atravesados por las ideologías dominantes de la época, las cuales marcan un campo de acción limitado. Esto es, la manera en que se reestructuran los sistemas humanos para sostener la vida colectiva, los que son resultado de las luchas que la gente realiza con el fin de hacerse de una vida, pueden reproducir, de manera intensificada, las condiciones de desigualdad que impone el capitalismo. Para ilustrar este tema se tomarán como eje de la discusión los conceptos de incertidumbre, valor y optimismo.

\section{La diversidad cultural: un valor en sí mismo}

Antes de involucrase en ceremonias "prehispánicas" y encontrar una forma de ganarse la vida a partir de ellas, gente como Xiuhtecuhti, Coyoltzin y Ameyal tuvieron trayectorias laborales e identitarias muy diversas. Entre los trabajos que habían tenido destacan los de albañil, vendedor de BonIce, ${ }^{3}$ cantar en el transporte público, guardia de seguridad o comerciante de artesanía. Sus identidades estaban ligadas a sus gustos musicales (rockero); a las actividades que realizaban con sus amigos del barrio, por ejemplo, patinar y hacer grafitis (skater); o al barrio de origen. Xiuhtecuhtli conoció la danza cuando, impresionado por el eclipse total de sol de 1991 y por las profecías mayas que habían predicho este fenómeno astronómico, decidió acercarse a su "verdadera" cultura. Poco tiempo después Ameyal, amigo con el que solía salir a patinar y grafitear, se unió a él. Dos décadas después Ameyal se separaría de Xiuhtecuhtli y comenzaría a trabajar por su cuenta. Coyoltzin, más joven que ellos dos, quedó maravillado cuando vio danzantes haciendo rituales en la pirámide de Cholula durante los festejos del equinoccio de primavera. Ese grupo de danzantes era dirigido por Xiuhtecuhtli. Coyolotzin se uniría a ellos, aunque posteriormente formó su propio grupo.

Todos ellos, así como otros danzantes en Cholula y la ciudad de Puebla, pasaron por un proceso mediante el cual se convirtieron en guardianes de la tradición. Desde entonces comenzaron a asistir y a participar en rituales celebrados por otros danzantes en diferentes lugares del país. Su forma de hablar cambió: agregaron a su vocabulario palabras de origen náhuatl, ideas sobre las tradiciones, cultura y legado prehispánico, así como referencias a una espiritualidad propia ligada a su verdadero origen étnico, azteca, mexica y/o cholulteca. Se identificaron como herederos directos de una forma de ver el mundo que se encontraba impresa en su sangre y que ahora resurgía debido al llamado que los había convocado a recuperar su verdadero "rostro y corazón".
3. Bonlce es una barra de sabores congelada que se ha hecho popular por sus reducidos costos. La forma en que se comercializa es mediante un pequeño ejército de vendedores que recorren las calles llevando un carrito con el producto. Por cada pieza vendida ganan un peso. Por lo general, son adultos mayores quienes obtienen estos empleos, por demás precarios.
4. Con estas palabras los danzantes suelen hacer referencia a la recuperación de su verdadera identidad, aquella negada por la conquista y siglos de colonización espiritual, intelectual, económica, política y cultural. 
Puesto que la cultura es el eje que articula las ideas y demandas de los danzantes de la mexicanidad, se impone como tema necesario en el presente análisis partir de una definición de este concepto que tenga la cualidad de hacer visibles las condiciones en que es movilizado de manera práctica. Si bien este concepto es uno de los más difíciles de definir debido a la gran cantidad de actividades e ideas con las que es posible asociarlo (Williams, 2000), por el momento, con la intención de mostrar y analizar cómo la noción de cultura es parte fundamental del surgimiento de los guardianes de la tradición, se la definirá como "aquello que hace que la vida valga la pena" (Eagleton, 2016, p. 13). Terry Eagleton, en su libro Culture (2016), hace notar que los humanos siempre necesitan de elementos simbólicos -cultura- para dotar de sentido a la vida más allá de las necesidades biológicas. Por ejemplo, para sobrevivir es necesario satisfacer dichas necesidades, comer y beber entre ellas; pero lo que no es biológicamente necesario es que la comida y bebida sean, en el primer caso, cocinada por un chef reconocido, o que forme parte de una reserva especial añejada por cien años, en el segundo. "Necesitas cabello para proteger tu cráneo, pero no hay necesidad de teñirlo de morado [...] estas necesidades excesivas pueden pensarse en sí mismas como una necesidad" (Eagleton, 2016, p. 24). El discurso multicultural, que da mayor importancia a la demanda de derechos culturales que a la lucha por derechos sociales, ha dado un empuje mayor a esta manera de entender la cultura.

La celebración de la diversidad cultural -principal objetivo y argumento del discurso multicultural-invita a reconocer el valor que tienen las culturas y las diferencias entre grupos e individuos independientemente de la posición que estos tienen en las relaciones sociales de producción. Es decir, la diversidad deja de ser un hecho de la realidad social y pasa a ser un valor en sí mismo (Eagleton, 2016). De este modo, todo individuo es valioso en la medida en que es portador de diferencias culturales que lo distingan de otros individuos y grupos. Aunque, claro está, el reconocimiento depende de la capacidad de demostrar esas diferencias y de que estas sean valoradas como inofensivas.

Los danzantes en Cholula obtienen reconocimiento -su vida es dotada de valor- y se ganan la vida -a partir de un servicio que tiene valor en el mercado- como guardianes de la tradición en la medida en que son capaces de mostrar, de manera consciente y explícita, que son portadores de diferencias culturales particulares. La noción de valor social (social worth) propuesta por Narotzky y Besnier puede complementar esta idea. Por valor social se debe entender "la manera en que una sociedad valora a las personas: el valor de las personas, pero también el valor que se obtiene a través de las personas y el valor invertido y acumulado en las personas" (Narotzky y Besnier, 2014, p. 10). Si bien hay diferentes formas de asignación de valor de las personas, vale la pena partir del contexto general en que esto sucede. Dos temas resaltan: el modo de producción y la ideología multicultural.

En el capitalismo, el valor de las personas depende de su estatus basado en la lógica de este modo de producción: por un lado, en la diferencia entre quienes solo tienen su fuerza de trabajo (proletariado) y quienes son propietarios de capital. Por otro, en el intercambio de mercancías y en el consumo. Esta doble asignación de valor es engañosa. En primer lugar, el valor de la gente se asigna dependiendo de su utilidad como medio para la reproducción del capital, esto a partir de relaciones sociales en las que solo un grupo reducido realmente puede acumular riqueza. En segundo término, se genera la idea equivocada de que todas las personas son iguales en el mercado: capitalistas cuyo objetivo final es la maximización de ganancias. La igualdad de las personas bajo la premisa de la libertad de intercambio y consumo en el mercado es engañosa, pues en realidad, esa supuesta igualdad sucede en condiciones desiguales, las cuales tienen su origen en un acceso diferenciado al poder y a la riqueza. Bajo estas contradicciones inmanentes de la lógica capitalista tiene lugar la búsqueda de la reproducción de la vida. 
De la misma forma, el valor que el multiculturalismo brinda a los representantes de la cultura presenta sus propias contradicciones. Una forma de evidenciarlas puede ser tomada del debate entre Slavoj Žižek y Sara Ahmed (Arenas, 2018b; Žižek, 2012b). De acuerdo con Ahmed, ${ }^{5}$ puesto que la corrección política multicultural no se traduce en verdaderos actos o prácticas que respeten la diferencia cultural, esta puede ser pensada como un "acto de habla no-performativo". Sin embargo, como lo señala Žižek, en ella hay una fuerza performativa que se ubica en las relaciones materiales basadas en la tolerancia multicultural, en el trasfondo del discurso. Ha terminado, con la intención de combatir el racismo clásico (Balibar, 1991), construyendo relaciones ancladas en un nuevo tipo de racismo, uno de tipo invertido. Se trata de actos de condescendiente celebración de la exótica autenticidad del Otro (Žižek, 2012b), aquella "actitud que trata a cada cultura local como el colonizador trata al pueblo colonizado: como 'nativos', cuya mayoría debe ser estudiada y respetada cuidadosamente" (Žižek, 1998, p. 172). Las contradicciones del multiculturalismo no se encuentran solo en la superestructura ni pueden ser resueltas en ese nivel, sino que están presentes en las prácticas que producen.

Los sujetos que hoy en día realizan rituales prehispánicos en Cholula solían ser albañiles -algunos aún lo son- o tenían formas de ganarse la vida que no generan el interés ni el reconocimiento de otras personas. Pero cuando se transformaron en guardianes de la tradición, el trato que comenzaron a recibir fue diferente. Se los reconoce como expertos rituales, conocedores de una cultura antigua e importante. La gente se acerca a tomarse fotos con ellos, les agradecen por su trabajo de preservación de la tradición y por compartirla con el resto del mundo. La vida de estas personas adquiere otro sentido y se convierte así en una vida que vale la pena ser vivida. Pero estas relaciones basadas en la tolerancia multicultural tienen límites y un trasfondo racista. El reconocimiento que se les da a los guardianes de la tradición no se basa en su estatus como personas o individuos; más bien, el valor que se les asigna depende de su rol como portadores o recipientes de una cultura particular.

Un dato de campo ayudará a ejemplificar lo dicho hasta este momento. De entre las muchas presentaciones en las que participé con los grupos de danzantes destaca una que se realizó en un salón jardín con motivo del bautizo de un niño. Cuando llegamos al lugar no estábamos vestidos con los trajes de danza; vestíamos ropa civil y, a diferencia de los invitados a la fiesta, lucíamos desarreglados. Encontramos una mesa casi vacía en la cual esperábamos sentarnos, al preguntar a las tres personas que se encontraban ahí si podíamos sentarnos en el resto de los asientos, respondieron que ya estaban ocupados. Intentamos en una segunda mesa y pasó lo mismo. Decidimos salir al estacionamiento para empezar a prepararnos para el ritual. Al salir, los danzantes comenzaron a comentar lo que había pasado: "como que la gente nos veía chistoso, ${ }^{6}$ ¿no?", "sí, sólo porque nos vieron vestidos así", "prefiero comer aquí afuera, mejor vamos a comprar al OXXO"; 7 uno más agregó, "yo ya estoy acostumbrado a que la gente me vea chistoso, mejor no les hago caso, me hago wey".

Cuando la ceremonia dio inicio volvimos a entrar, pero esta vez lo hicimos con nuestros trajes de danza, plumas y maquillaje. Se escuchaban los tambores y ocarinas, y el humo de copal generó un ambiente de misticismo. La gente se reunió a nuestro alrededor, tomaron fotos, algunos imitaron los pasos de danza; al final se formaron para que se les hiciera una limpia con copal y nos felicitaron por la presentación. La identidad cultural bajo la cual nos presentamos fue merecedora de respeto, mientras que las diferencias que mostramos como parte de nuestras identidades sociales no lograron inspirar admiración ni confianza.

Las contradicciones del multiculturalismo no se encuentran solo en su discurso, sino que se construyen y reafirman en la práctica en la medida en que forman parte de las
5. Los argumentos de Ahmed aparecen en la obra de Žižek, en la cual se presenta un resumen del debate.

6. Se refiere a que la gente nos miró de manera despectiva.

7. Un OXXO es una cadena de tiendas de conveniencia. En México, las sucursales de esta cadena han sustituido en gran medida las antiguas "tienditas" familiares; esto se debe a que ofrecen productos y precios estandarizados.

8. El mexicanismo wey es utilizado de distintas formas, para referirse de manera informal sobre alguien sin usar su nombre, como expresión peyorativa y, en el caso de la expresión utilizada por mi informante, para señalar desentendimiento o hacer caso omiso de alguna situación o comentario. 
relaciones materiales que se establecen entre aquellos que celebran, respetan y admiran la diversidad cultural y quienes encarnan dichas diferencias. El discurso multicultural, a la par de los nuevos mercados creados por el neoliberalismo, ha construido formas de asignación de valor de las personas que, por un lado, permiten a una fracción de la población obtener cierto valor en el mercado, lo cual se traduce en una oportunidad de transferir el valor ganado a sus familias. Por otro, el valor que se le da a la diversidad cultural genera una dignidad sostenida por un reconocimiento incompleto.

\section{Optimismo e incertidumbre: dos caras de la misma moneda}

La crisis puede ser definida como un momento de incertidumbre radical, situación en la que se genera una "brecha en la confianza de la gente en los elementos que proveen una relativa estabilidad sistemática y expectativas razonables hacia el futuro" (Narotzky y Besnier, 2014, p. 4). Aunque suele asumirse que en la historia del capitalismo las crisis son anomalías, eventos poco comunes resultado de malas decisiones o del actuar corrupto de ciertos personajes (Sen, 2009) o producto de lo imprevisible de la dinámica del mercado (Kawashima, 2009), en realidad son los momentos de menor incertidumbre los que ocurren con poca frecuencia (Harvey, 2014). La incertidumbre no es tan solo un error, tampoco es producto de la mala suerte o de una mala organización individual, se trata de una de las principales características de la vida en el capitalismo.

Si bien este sistema puede tomar diferentes formas (industrial, comercial, financiero, entre otras), uno de sus componentes básicos y más duraderos, la mercancía, refleja fielmente la incertidumbre como una de sus características inmanentes. La relación entre mercancía e incertidumbre puede ser pensada desde dos de sus expresiones: los bienes de uso y cambio, y la mercancía fuerza de trabajo. En lo que se refiere al primer tipo, el valor de las mercancías solo tiene sentido una vez que se lleva a cabo el intercambio, es decir, cuando la mercancía es comprada y con ello el plusvalor se realiza. Cuando una mercancía se encuentra en la estantería de alguna tienda su valor se mantiene congelado, es tan sólo una promesa, la creencia de que en algún momento se realizará (Karatani, 2005). Sin embargo, el momento del intercambio puede que nunca llegue y con ello el proceso capitalista se viene abajo.

Kojin Karatani ha llamado a esta característica de las mercancías un "salto mortal", pues el capital no puede ser recuperado, multiplicado, acumulado y reinvertido si la promesa de que la mercancía será comprada no sucede (Karatani, 2005). La lógica en la que opera la mercancía fuerza de trabajo es la misma. Como ya se ha dicho páginas arriba, el proletariado solo cuenta con su fuerza de trabajo para lograr la reproducción social, no obstante, nada asegura que ésta se realizará, independientemente de que esta sea puesta a la venta o se utilice de manera autónoma fuera de toda relación contractual, tal como sucede con los danzantes y la producción de renta por monopolio. Esta incertidumbre es propia del hecho de tener que salir a ganarse la vida todos los días.

Aunque la incertidumbre, la forma en que se experimenta la crisis, es la base sobre la cual el capitalismo opera, la manera en que se habla sobre ello puede variar. De acuerdo con Macip (2005), en México se construyó una narrativa sobre la crisis a partir de 1982, momento en que fue implementada una serie de ajustes estructurales en términos políticos, económicos y culturales, que posteriormente serían conocidos como neoliberalismo. El proyecto neoliberal, con su tendencia hacia el libre mercado, comenzó con la desarticulación del Estado benefactor y propició la flexibilización laboral, mediante el ataque directo a la organización obrera y los derechos laborales. La narrativa de la crisis, su legítimo y urgente combate, permitió el reordenamiento de la fuerza de trabajo y formas de disciplinamiento que, de manera conjunta, tuvieron como resultado la explotación intensificada y el empobrecimiento del proletariado. De 
tal forma la crisis, propone Macip, puede entenderse como una manera localizada de experimentar el neoliberalismo (Macip, 2005).

Actualmente vivimos en un momento en que aquellos ajustes estructurales que iniciaron en 1982 se encuentran, si no consolidados, al menos más desarrollados y por lo tanto, sus contradicciones son más evidentes. Con ello, la incertidumbre radical y la desigualdad económica han aumentado (Piketty, 2014). Sin embargo, la narrativa de la crisis parece haber desaparecido o se ha trasladado hacia temas ambientales, migratorios y de violencia, mismos que siempre terminan siendo tratados en términos culturales (por ejemplo, ausencia de una cultura ambiental, la emergencia de una cultura del narco). Mientras la narrativa sobre la crisis estuvo vigente, las expectativas que la gente tenía sobre el futuro eran desalentadoras (Macip, 2005); ahora el emprendedurismo ha generalizado la idea de que el futuro puede ser mejor, pues depende del trabajo duro que cada individuo pueda hacer por su cuenta.

Jorge Alemán (2013) ha señalado que el neoliberalismo produce subjetividades bajo estas premisas, lo cual genera la idea de que cada quien puede ser su propio jefe y dueño de su tiempo y trabajo, y con ello tomar las riendas de su propia vida. Se trata de la subjetividad del empresario o "emprendedor de sí mismo" (Alemán, 2013). Esta supuesta autonomía frente al mercado genera un optimismo que, a pesar de estar sustentado en la incertidumbre que el neoliberalismo ha creado, permite imaginar el futuro de manera más positiva. Aunque, por supuesto, esto no quiere decir que el futuro realmente será mejor.

Cabe aclarar este tema: el emprendedor no es víctima de una falsa conciencia, esto es, no se encuentra simplemente cegado por la ideología, pues es capaz de ver y entender que sus condiciones materiales de vida son desfavorables, que la incertidumbre es algo cotidiano en su experiencia diaria. Sin embargo, el hecho de superar la falsa conciencia no implica que sus actividades estén libres del trabajo de la ideología. Si bien el empresario de sí mismo puede estar al tanto de las condiciones desfavorables en las que vive, en el momento en que realiza las relaciones con las cuales intenta hacerse de una vida pareciera que aquella incertidumbre desaparece o, al menos, es pasada de largo.

Frente a la vieja noción de falsa conciencia propuesta por cierto marxismo, Žižek muestra que los sujetos pueden conocer algunos aspectos de la máscara ideológica; sin embargo, eso no implica que puedan darse cuenta de que la realidad se encuentra estructurada a partir de una fantasía. Por ejemplo, es bien sabido por todos que el dinero no tiene valor por sí mismo, esto es, que el valor que tienen billetes y monedas no se encuentra dentro de ellos, sino que es resultado de relaciones sociales entre personas. A pesar de que los sujetos identifican bien la máscara ideológica que mistifica relaciones entre personas bajo la apariencia del dinero, cuando actúan e intercambian monedas lo hacen como si fueran la encarnación de la riqueza. En palabras de Žižek, "lo que reconocen falsamente es el hecho de que, en su realidad social, en su actividad social -en el acto de intercambio de mercancías- están orientados por una ilusión fetichista" (Žižek, 2012a, p. 59).

Coyoltzin y Xiuhtecuhtli son un buen ejemplo de la forma en que se conforma la subjetividad del empresario de sí mismo en un contexto de incertidumbre radical. En diferentes momentos, Xiuhtecuhtli me comentó que lo que él hace -organizar a otros danzantes- es "algo así como mi propia empresa". A pesar de que todos los días se encuentra en una difícil lucha para lograr la reproducción social de su familia, caminando en los alrededores de la pirámide de Cholula, expuesto al sol intenso, tratando de cautivar al turismo para que se tomen una foto con él, experimentando la incertidumbre de salir a ganarse la vida sin saber cuánto logrará recaudar, siente cierta satisfacción al pensarse como su propio jefe. Imagina un futuro en el que no tendrá 
que danzar todo el tiempo ni realizar largas caminatas buscando turismo; en lugar de eso, solo organizaría a otros danzantes a los que mandaría a cubrir lugares designados, previamente pactados y con los respectivos permisos administrativos.

Por su parte, Coyoltzin tuvo la oportunidad de obtener un puesto de trabajo seguro y con prestaciones como maestro de danza en la casa de la cultura de San Pedro Cholula. Sin embargo, a pesar de haber reunido los documentos que le solicitaron, finalmente decidió no aceptar el trabajo. Al preguntarle el motivo, me dijo que, tener un trabajo con horarios fijos y con alguien con un puesto superior al suyo que le pediría resultados no le permitiría tener la libertad de la que goza actualmente. Los días que tiene resueltas sus necesidades inmediatas puede decidir no salir a trabajar, cuando tiene algún compromiso ritual con danzantes de otros lugares puede dejar sus actividades en Cholula y viajar para cumplir con esos compromisos. Además, ser su propio jefe y seguir siendo la imagen oficial de Cholula Pueblo Mágico es algo que lo llena de orgullo. Coyoltzin aspira a seguir siendo su propio jefe ganándose la vida a partir de sus actividades como danzante; además, tiene como objetivo abrir un negocio en el que pueda vender pulque y ofrecer servicios de ceremonias de temazcal para turistas $\mathrm{y}$ aquellas personas interesadas en vivir la experiencia.

La forma en que se imagina el futuro no siempre se encuentra directamente informada por las condiciones en que se vive. En el caso de los guardianes de la tradición, la incertidumbre que experimentan de manera cotidiana parece no ser tomada en cuenta en el momento en que, de manera optimista, se construyen expectativas hacia el futuro desde el presente. El trabajo de mistificación ideológica del emprendedurismo no actúa cegando a los sujetos, pues estos son capaces de ver las condiciones precarias en las que se encuentran. Sin embargo, genera cierto optimismo que les permite imaginar el futuro de manera más positiva en la medida en que asumen que este solo depende de su esfuerzo individual. Puesto que la forma en que luchan para hacerse de una vida se encuentra directamente ligada a la premisa multicultural de la celebración de la diversidad, sus esfuerzos, imaginación, creatividad y capacidad de análisis siempre se encuentran mediados por el tema de la cultura y la identidad, de tal modo que sus estrategias económicas y políticas se encuentran recubiertas o mistificadas por lo cultural.

Una vez desarrollado este argumento sobre el emprendedurismo se vuelve evidente una contradicción. Por un lado, las actividades de los danzantes siempre son presentadas como un trabajo de defensa y difusión cultural, lo cual se sintetiza en el uso de la palabra "cooperación", que sustituye a otras que tienen una connotación económica, tales como sueldo y pago. Por otro, los casos de Xiuhtecuhtli y Coyoltzin, dirigentes de grupos, muestran que son conscientes de que sus actividades "culturales" se encuentran atravesadas por lo económico y lo político. ¿Esta contradicción reside en un error del presente análisis, en cierto cinismo de los guardianes de la tradición, o podría ser una contradicción propia de los nuevos mercados laborales que ha construido el neoliberalismo?

\section{A modo de cierre}

Para dar respuesta a la pregunta que quedó abierta, y para presentar unas reflexiones finales, quiero desarrollar un dato de campo más. Durante una de las celebraciones del equinoccio de primavera, Coyoltzin y su grupo de danzantes -en el cual yo estaba incluido- fue invitado a participar en un evento oficial organizado por el gobierno de San Andrés Cholula. El público que estaba reunido a su alrededor vestía de blanco y se encontraba ansioso por seguir las indicaciones del ritual. Cuando Coyoltzin, con micrófono en mano, pidió que la gente levantara las manos dirigiéndose hacia el sol, todos lo hicieron; cuando pidió que gritaran "Quetzalcoatl", hubo una fuerte respuesta 
grupal. El presidente municipal agradeció a los guardianes de la tradición por dirigir el ritual, y convocó a sus conciudadanos a no olvidar la gran labor de rescate cultural que los danzantes realizan.

Al finalizar regresamos a San Pedro Cholula -caminamos unos doscientos metros-, a la explanada que se encuentra frente a la pirámide, lugar donde Coyoltzin tiene un amplio puesto en donde vende artesanías. Cuando llegamos, el líder de los comerciantes de la zona se acercó a él: “¿van a danzar?, la gente no se está acercando, se pasan derecho hacia el zócalo. Cuando ustedes danzan 'jalan" a la gente con el ruido de los tambores y sus gritos. ¿A qué hora van a empezar a danzar?”. Era evidente que estaba moderando su voz; realmente quería que Coyoltzin pusiera a danzar a su gente para que el turismo se reuniera y el comercio se activara.

El 21 de marzo es un día de venta importante, los comerciantes pagan al Ayuntamiento un derecho de piso por dos semanas; sin embargo, el momento en que realmente pueden vender es ese día. Si el 21 no hay venta, es posible que no puedan recuperar ni siquiera la inversión por el permiso de comercio. Una vez que el comerciante se fue, le pregunté a Coyoltzin si danzaríamos; me dijo que sí, pero que esperaría un poco más. Antes de que pudiera preguntarle por qué, se adelantó a decir:

aquí los que verdaderamente 'chambeamos ${ }^{10}$ somos los danzantes, estamos bajo el sol, nos quemamos los pies, nos cansamos, mientras los comerciantes están sentados en la sombra aprovechando la gente que atraemos. Si ese 'wey'11 -el líder de los comerciantes- hubiera llegado con un refresco o se 'mochara' ${ }^{12}$ con algo, las cosas serían diferentes, pero no, solo esperan que trabajemos para ellos de a gratis. (Conversación con Coyoltzin, marzo 2017, Cholula)

A pesar de que la contribución que el grupo de Coyoltzin hace a la economía de la zona es evidente para quienes se benefician de ellos -comerciantes, empresarios y políticos-, la forma en que se habla sobre sus actividades es bajo el filtro de la cultura. Es común que quienes tienen puestos de venta o pequeños comercios alrededor de la pirámide pasen a hacerse una "limpia"13 cuando los danzantes están haciendo rituales. Incluso, en ocasiones, aquellos llegan a pedirles que hagan ceremonias especiales para honrar a la Virgen de los Remedios, patrona de "las Cholulas". Como se señaló anteriormente, nunca se habla sobre pagar por los rituales; siempre se maneja como dar una "cooperación" a los "guardianes de la tradición", una contribución para que la cultura se mantenga. Esta contradicción no es más que otra expresión de aquella antes señalada en sus actividades. Ambas son generadas por la combinación entre multiculturalismo y mercado laboral neoliberal. Hasta cierto punto, los comerciantes pueden ser conscientes sobre cómo esas personas que hacen ceremonias de inspiración prehispánica permiten generar rentas por monopolio; al mismo tiempo, están dispuestos a que les hagan "limpias" a ellos y a sus puestos, y tratarlos como expertos rituales de la cultura antigua. Es decir, la forma en que se relacionan con ellos es bajo la categoría cultural de los guardianes de la tradición.

El análisis hasta aquí presentado ha intentado ampliar el entendimiento del ámbito de la economía a partir de la noción de hacerse de una vida, abriendo la posibilidad de ir más allá de los análisis anclados en el mecanicismo de la transacción económica básica. Los juegos del discurso cultural, así como las relaciones materiales que los sustentan, generan un primer plano de observación que debe ser trascendido para encontrar la lógica que da estructura a las diversas formas en que la fuerza de trabajo es movilizada en la actualidad. Mostrar este proceso de reorganización del mercado laboral, vinculado a las luchas diarias y a las estrategias que la gente realiza para hacerse de una vida, permite crear una radiografía que muestre la ruta que estas toman de manera cotidiana, así como de sus límites.
9. Atraen.

10. Trabajamos.

11. En este caso, el uso del mexicanismo "wey" se refiere a una forma coloquial o informal de llamar a una persona.

12. Término coloquial y sinónimo de compartir, invitar, dar parte de. También utilizado para referirse a la acción de ofrecer algo en un acto de corrupción.

13. Una "limpia” es la forma común de llamar a los rituales de purificación del cuerpo y “el espíritu", en los cuales se utilizan resinas aromáticas como el copal, plantas medicinales, entre ellas el romero, hinojo y pericón, y piedras a las que se les atribuyen propiedades energéticas, como el cuarzo y el jade 
Los guardianes de la tradición pueden organizar sus estrategias para lograr la reproducción de la vida y, al mismo tiempo, dotarlas de valor a partir de los nuevos espacios que el mercado ofrece; no obstante, entre más esfuerzo hagan por conseguir reconocimiento en términos meramente culturales e identitarios, más se alejan de las condiciones reales que los mantienen en desventaja en términos económicos y políticos. Esto es, pierden incluso la posibilidad de identificar aquellos procesos y relaciones que generan la desigualdad, de esta forma, la vulnerabilidad que marca su posición como fuerza de trabajo seguirá reproduciéndose. Los conceptos de incertidumbre, optimismo y valor (en términos económicos, culturales y morales) permiten mostrar esos procesos, pues hacen evidente cómo la cultura es movilizada para reproducir las relaciones asimétricas en el capitalismo y, en consecuencia, los límites de las estrategias que la población desposeída moviliza para hacerse de una vida en tiempos del multiculturalismo neoliberal.

\section{Sobre el autor}

Maestro en Antropología Sociocultural por el ICSyH-BUAP, generación 2015-2017. Alumno de Doctorado en Antropología Social en Ciesas-Sureste, generación 2019-2023.

\section{Financiamiento}

Investigación financiada por el Consejo Nacional de Ciencia y Tecnología, Conacyt, México.

\section{Agradecimientos}

Agradezco al Consejo Nacional de Ciencia y Tecnología el financiamiento otorgado para realizar la tesis de maestría "La cultura no es mercancía": subjetividad, etnicidad y proletariado entre los danzantes de la mexicanidad en Cholula, Puebla. Y por el financiamiento vigente para cursar el programa de doctorado.

Asimismo, agradezco a quienes se encargaron de evaluar la pertinencia y coherencia del presente artículo, y a la correctora de estilo, por sus valiosos comentarios, recomendaciones bibliográficas y su minucioso trabajo de corrección. En particular, me siento en deuda por la sugerencia de incorporar la propuesta de David Harvey sobre renta por monopolio pues, más que complementar mi análisis, me ha permitido profundizar y ampliar sus alcances. 


\section{Q Referenicas bibliográficas}

》Alemán, J. (2013). Neoliberalismo y subjetividad. Página 12. Recuperado de https://www. pagina12.com.ar/diario/contratapa/13-215793-2013-03-14.html

" Arenas, L.A. (2018a). "La cultura no es mercancía": subjetividad, etnicidad y proletariado entre los danzantes de la mexicanidad en Cholula, Puebla. (Tesis de maestría inédita). Instituto de Ciencias Sociales y Humanidades "Alfonso Vélez Pliego" BUAP, Puebla, México.

» Arenas, L.A. (2018b). El proletariado del multiculturalismo: sujetos multiculturales y la cultura como nicho de mercado en Cholula, Puebla. Revista Ciencia, 4, 22-29.

" Arenas, L.A. (2018c). Negociando la identidad en un Pueblo Mágico: los danzantes de la mexicanidad en Cholula, Puebla. En Jornadas de Americanística. Coloquio sobre cuatro temas relevantes de la americanística actual. Centro Studi Americanistici "Circolo Amerindiano", Universidad Nacional Autónoma de México, Ciudad de México, México.

" Arenas, L.A. (2019). Los danzantes de la mexicanidad en Cholula, Puebla (México): ¿guardianes de la tradición o proletariado del multiculturalismo? Revista Latinoamericana de Antropología del Trabajo, 3(6). Recuperado de http://www.ceil-conicet.gov.ar/ojs/ index.php/lat/article/view/482

》 Balibar, E. (1991). Is There a Neo-racism? En E. Balibar e I. Wallerstein (Eds.). Race, Nation and Class Ambiguous Identities (pp. 17-28). Londres: Verso.

》 Boltanski, L. y Chiapello, È. (2002). El nuevo espíritu del capitalismo. Madrid: Akal.

»Cohen, E. (1988). Authenticity and Commoditization in Tourism. Annals of Tousim Research, 15, 371-386. doi: 0.1016/0160-7383(88)90028-X

" Comaroff, J. y Comaroff, J. (2011). Etnicidad S.A. Buenos Aires: Katz.

» De la Peña, F. (2002). Los hijos del sexto sol. Ciudad de México: Instituto Nacional de Antropología e Historia.

》 De la Torre, R. (2007). Estética azteca de las danzas concheras. Tradiciones exóticas o memorias re-descubiertas. Revista Versión. Estudios de comunicación y política, 20, 147186.

"Denning, M. (2010). Vida sin salario. New Left Review, 66, 77-94.

"Eagleton, T. (2016). Culture. Yale: Yale University Press.

"Escalona, J. L. (2016). Etnomercancía y sobrefetichización. Ensayo de mirada estereográfica. Relaciones Estudios de Historia y Sociedad, 148, 259-288. Recuperado de https:// www.colmich.edu.mx/relaciones25/index.php/numeros-anteriores/10-articulos/2040articulo-148-etnomercancia-y-sobrefetichizacion-ensayo-de-mirada-estereografica

» Frigolé, J. (2014). Retóricas de la autenticidad en el capitalismo avanzado. Éndoxa: Series Filosóficas, 33, 37-6o. doi: https://doi.org/10.5944/endoxa.33.2014.13564

》 Galinier, J. y Molinié, A. (2013). Los neo-indios. Una religión del tercer milenio. Quito: AbyaYala.

》Harvey, D. (2005). El arte de la renta: la globalización y la mercantilización de la cultura. En D. Harvey e Y. N. Smith (Eds.), Capital financiero, propiedad inmobiliaria y cultura (pp. 29-58). Barcelona: Universidad Autónoma de Barcelona. 
» Harvey, D. (2012). La condición de la posmodernidad. Investigaciones sobre los orígenes del cambio cultural. Buenos Aires: Amorrortu.

» Harvey, D. (2014). Seventeen Contradictions and the End of Capitalism. Oxford: Oxford University Press.

» Harvey, D. (2015). Breve historia del neoliberalismo. Madrid: Akal.

» Jameson, F. (2012). Posmodernismo. La lógica cultural del capitalismo avanzado. Vol. I. Buenos Aires: La Marca Editora.

» Karatani, K. (2005). Transcritique: on Kant and Marx. Massachusetts: MIT Press.

» Kawashima, K. (2009). The Proletarian Gamble. Korean Workers in Interwar Japan. Londres: Duke University Press.

» MacCanell, D. (2013). The Tourist: a New Theory of Leisure Class. Berkeley: University of California Press.

" Macip, R. F. (2005). Semos un país de peones: café, crisis y el estado neoliberal en el centro de Veracruz. Puebla: Buap.

»Mandel, E. (1979). El capitalismo tardío. Ciudad de México: Era.

» Narotzky, S. y Besnier, N. (2014). Crisis, Value, and Hope: Rethinking the Economy. An Introduction to Supplement 9. Current Anthropology, 5, S4-S16. doi: https://doi. org/10.1086/676327

» Organización Mundial del Turismo (OMT). (2001). Código ético mundial para el turismo. Por un turismo responsable. Organización Mundial del Turismo y Naciones Unidas.

»Pérez, B. (2006). Turismo y representación de la cultura: identidad cultural y resistencia en comunidades andinas del Cusco. Anthropologica, 24(24), pp. 29-49. Recuperado de http://www.scielo.org.pe/scielo.php?script=sci_arttext\&pid=So254$92122006000100002 \& \operatorname{lng}=e s \& n r m=i s o$. ISSN $0254-9212$.

» Picard. M. (1997). Cultural Tourism, Nation-Building, and Regional Culture: The Making of a Balinese Identity. En M. Picard y R. Wood (Eds.). Toursim, Ethnicity, and the State in Asian and Pacific Societies (pp. 181-214). Honolulu: University of Hawaii Press.

» Piketty, T. (2014). El capital en el siglo XXI. Ciudad de México: Fondo de Cultura Económica.

»Sen, A. (2009). Capitalism Beyon the Crisis. New York Review of Books, 56(5). Recuperado de http://nrs.harvard.edu/urn-3:HUL.InstRepos:2961699

» Sider, G. (2003). Between History and Tomorrow. Making and Breaking Everyday Life inRural Newfoundland. Toronto: Broadview Press.

»Urry, J. (2018). La mirada del turista. Revista Turismo y Patrimonio, 3, 51-66. Recuperado de http://ojs.revistaturismoypatrimonio.com/index.php/typ/article/view/153

»Williams, R. (200o). Palabras clave. Un vocabulario de la cultura y la sociedad. Buenos Aires: Nueva Visión.

» Xie, P. F. (2011). Authenticating Ethnic Tourism. Ontario: Channel View Publications.

» Žižek, S. (1998). Multiculturalismo, o la lógica cultural del capitalismo multicultural. En F. Jameson y S. Žižek (Eds.). Estudios culturales. Reflexiones sobre el multiculturalismo (pp. 137-188). Buenos Aires: Paidós.

» Žižek, S. (2012a). El sublime objeto de la ideología. Ciudad de México: Siglo Veintiuno.

» Žižek, S. (2012b). Viviendo en el final de los tiempos. Madrid: Akal. 